\title{
Handling of endoscopic equipment after use in the case of a patient with suspected prion disease
}

\author{
Jolanta Gruszecka ${ }^{1,2, B-D, F \oplus}$, Rafal Filip ${ }^{3,4, A, D-F} \oplus$ \\ ${ }^{1}$ Institute of Nursing and Health Sciences, Medical Faculty, University of Rzeszów, Poland \\ ${ }^{2}$ Clinical Department of Microbiology, Regional Clinical Hospital No. 2, Rzeszów, Poland \\ ${ }^{3}$ Medical Faculty, University of Rzeszów, Poland \\ ${ }^{4}$ Gastroenterology Clinic with Centre for Comprehensive Treatment of Non-specific Inflammatory Bowel Diseases, Clinical \\ Provincial Hospital No. 2, Rzeszów, Poland \\ A - Research concept and design, B - Collection and/or assembly of data, C - Data analysis and interpretation, \\ $D$ - Writing the article, E - Critical revision of the article, F - Final approval of article
}

Gruszecka J, Filip R. Handling of endoscopic equipment after use in the case of a patient with suspected prion disease. Ann Agric Environ Med. 2020; 27(3): 319-325. doi: 10.26444/aaem/111723

\section{Abstract}

Introduction. Prion diseases are slow-acting, neurodegenerative diseases found in humans and many species of animals. Although they occur very rarely in humans, currently, an increase in this type of disease is being observed, probably as a result of exposure to infectious prions causing BSE disease in cows.

Objective. The aim of the procedures described in the article is to minimize the risk of human-to-human transfer of all forms of transmissible spongiform encephalopathy, including variant CJD (vCJD) by contaminated medical equipment. Brief description of the state of knowledge. All diseases caused by prions, referred to as transmissible spongiform encephalopathies, are fatal. They are characterized by a long development period (up to several decades). Enormous problems are connected with the risk of transferring prions from patient to patient on the surface of instruments used in medical procedures. Laboratory tests indicate that standard disinfection and sterilization procedures may be insufficient to completely remove infectious proteins from contaminated instruments. One of the methods of infection prevention involves taking equipment used for surgery within the brain, tonsils or appendix, into quarantine until biopsy results of these organs have been received that exclude, as far as possible, asymptomatic carriage of prions.

Conclusions. Whenever possible and justified, disposable-use instruments should be used for invasive surgery in patients with definite, clinically probable cases of CJD (vCJD). After use, these instruments should be incinerated.

\section{Key words}

infections, prion protein, decontamination

\section{INTRODUCTION}

Prion diseases are a group of deadly neurological diseases due to the improper folding of the cellular prion protein (PrPC) inta a pathogenic form $\left(\mathrm{PrP}^{\mathrm{sC}}\right)$, mainly in the brain, but also in other tissues [1]. The $\operatorname{PrP}^{\mathrm{SC}}$ protein may cause incorrect folding of subsequent $\mathrm{PrP}^{\mathrm{C}}$ proteins and cause various diseases in the same host species [2,3]. Prion diseases affect both humans and various animals. These include scrapie and goat scrapie, bovine spongiform encephalopathy, chronic, debilitating deer disease and Creutzfeldt-Jacob disease in humans. These disorders can be sporadic, inherited, or acquired by infection [2].

The variant Creutzfeldt-Jakob disease (vCJD) is an infectious form of spongiform encephalopathy considered to be transmitted by eating beef infected with bovine spongiform encephalopathy (BSE). Tissue distribution of the infectious agent - cellular prion protein $\left(\mathrm{PrP}^{\mathrm{C}}\right)$, known as a prion $\left(\mathrm{PrP}^{\mathrm{TSE}}\right)$, is generally limited to the central nervous system, small amounts of infectious agent can be detected in biological fluids and in selected tissues [4]. Prions enter the living organism through the intestinal epithelium via $\mathrm{M}$ cells

Address for correspondence: Jolanta Gruszecka, Institute of Nursing and Health Sciences, Medical Faculty, University of Rzeszów, Poland

E-mail: jagrusz@onet.pl

Received: 28.04.2019; accepted: 07.08.2019; first published: 15.11.2019 into Peyer patches, accumulate in follicular dendritic cells. Dissemination in the CNS probably occurs through autonomic innervation of lymphoid tissues, after a period of incubation in the lymphoreticular system which may last several years [5-8]. In general, Creutzfeldt-Jakob disease is characterized by rapid deterioration of the mental state, usually preceded by various of symptoms, including personality changes, anxiety, depression, memory loss, blurred vision or blindness, insomnia, difficulties in speaking and swallowing, etc. To-date, approximately $230 \mathrm{vCJD}$ cases have been reported in 12 countries, mostly in Ireland, the United Kingdom and France [5]. What is important, is that a number of the transmissions of vCJD were considered iatrogenic and have been linked to the infusion of blood products $[6,7]$. There is also a suspicion that some cases can be attributed to previous surgery $[8,9]$, since it is evidenced that the transferred agent adheres to steel and is not completely inactivated by conventional sterilization procedures $[10,11]$. Even in asymptomatic individuals, pathological prions $\left(\mathrm{PrP}^{\mathrm{SC}}\right)$ can be present in lymphatic tissue, such as, for example, the tonsils, appendix and Peyer's patches. Prion diseases require long periods of replication so that the infectious agent can reach the target organ and cause damage to the CNS leading to the occurrence of clinical symptoms $[12,13]$.

Although as yet there are no proven examples of vCJD acquisitions during gastro-intestinal endoscopy, it must be pointed out that the risk of transmission is theoretically higher 
when compared to conventional surgery, since the operating channel of endoscopes, as well as re-usable endoscopy biopsy devices, could become contaminated. Modern endoscopes are complicated devices that are difficult to sterilize and susceptible to damage by chemicals and high temperature. Moreover, currently there are no validated methods of sterilization, including autoclaves, that can provide confidence of complete eradication of the prions that may cause vCJD. Therefore, general recommendations indicate the use of disposable equipment when possible $[13,14]$.

This review describes the possible risks of transmission through endoscopic procedures followed by some recommendations on how to minimize the threat.

Characteristics of prions. According to the protein hypothesis, the infectious proteins called prions consist of an isomerically-modified form of a normal cellular protein [15]. In the cell they have the ability to induce conformational changes of normal protein (non-infective) structures into infectious forms. In this way, prion proteins can replicate and infect other cells in the body $[16,17]$.

In the prion infection protein the proportion of $\alpha$-helical structures is smaller than in natural prion proteins, while the proportion of $\beta$-folding ( $\beta$-fold) structures is larger than in natural prion proteins. The erroneous folding of a normal prion protein $\left(\mathrm{PrP}^{\mathrm{C}}\right)$ into conformers $\left(\mathrm{PrP}^{\mathrm{SC}}\right)$ with the accumulation of $\mathrm{PrP}^{\mathrm{SC}}$ in the brain supports the transmission process [18]. The mutated forms of proteins are able to survive in extreme conditions [19].

In 1982, Stanley B. Prusiner introduced the name for infectious molecules - prions (from proteinaceous infectious particle - an infectious protein molecule) $[7,20]$.

Prions are infectious protein molecules; they cause neurodegenerative diseases of the nervous system [21]. Prion protein $(\mathrm{PrP})$ was first detected in the brains of sheep suffering from scrapie. For this reason, they were marked with the sign SC, to distinguish them from ordinary, socalled cellular, proteins marked with the C-sign. $\operatorname{PrP}^{\mathrm{C}}$ proteins occur naturally in nerve cells. Prions consist of the protein itself, they do not contain DNA or RNA, and it is the twisting and flattening of the polypeptide chains that gives them disease-causing features (Fig. 1). Further studies have shown that pathogenic prions are resistant to the proteolytic enzyme, protease $\mathrm{K}$; healthy prion protein is susceptible to protease. They are extremely resistant to conventional reprocessing procedures which neutralise many other germs, their particular shape provides great resistance to high temperatures. Therefore, they can be spread by nonsterilized medical tools [7, 22].

$\operatorname{PrP}^{\mathrm{c}}$ prion proteins have an $\alpha$-helical structure; when they change their shape into a folded $\beta$ structure they become an infectious $\mathrm{PrP}^{\mathrm{sc}}$ prion protein. Conformation changes the properties of proteins, thus having a direct impact on the principles of tool reprocessing (Table 1) [23].

Table 1. Properties of prion proteins (own preparation based on [22])

\begin{tabular}{ll}
\hline Normal prion proteins $\mathrm{PrPc}$ & Infectious prion protein $\mathrm{PrPsc}$ \\
\hline Soluble in water & Insoluble in water \\
\hline Not agglomerating & Agglomerating \\
\hline Decomposed by proteolytic enzymes & Resistant to proteolytic enzymes \\
\hline
\end{tabular}

Prion diseases. Prion diseases are contagious neurodegenerative disorders. In humans, they can cause Creutzfeldt-Jakob disease (CJD), vCJD disease - a variant of Creutzfeldt-Jacob disease and Kuru disease [18, 24, 25]. Major animal diseases include scrapie of sheep and goats, bovine spongiform encephalopathy, chronic debilitating disease of cervids and camel prion disease (identified in 2018) [25]. The debilitating disease of cervids has spread in North America and has recently appeared in Norway and Finland $[18,26]$. All diseases caused by prions, referred to as transmissible spongiform encephalopathies, are lethal. They can be transmitted within a species or between species, including zoonotic transmission to humans [27]. Prion diseases, associated with the accumulation of abnormal

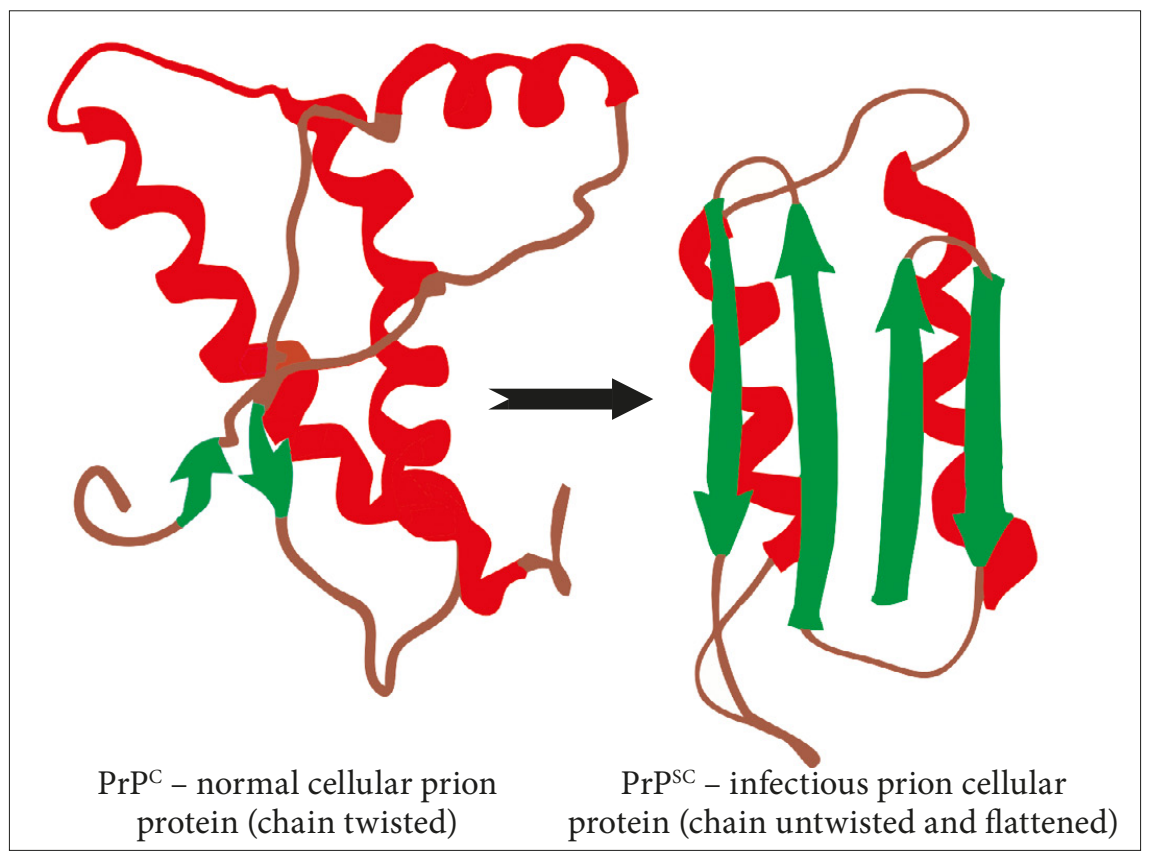

Figure 1. Diagram of conformational changes during the transformation of a natural prion protein into a prionic infectious protein (own preparation) 
forms of protein in the brain and other tissues, are extremely contagious $[3,24,26,27]$. They are characterized by a long development period (up to several decades).

1) Creutzfeldt-Jacob disease (CJD) - symptoms of the disease: muscle tremors, emotional changes, balance disorders, memory loss, drowsiness, lethargy, speech disorders, coma. It has been observed around the world. It is genetically determined in about $10-15 \%$ of cases - fCJD. It can be transmitted as a result of medical procedures (iatrogenic form - iCJD). Iatrogenic cases occurred after the administration of contaminated growth hormone obtained from the human pituitary gland, after dura mater implantation, after corneal implantation, after treatment with gonadotropin hormone derived from pituitary gland extraction, and due to contaminated surgical instruments. Sporadic Creutzfeldt-Jacob disease - sCJD, is associated with gene mutation, its aetiology is not fully understood. The incidence of sCJD is estimated at $1-2$ per 1 million population. In classic CJD disease, prion proteins are concentrated in the central nervous system, less frequently in other organs.

2) vCJD disease - a variant of Creutzfeldt-Jacob disease that is transmitted by infectious prions from animals suffering from BSE. It is characterized by a short incubation period and symptoms that include mental disorders, personality changes and aggression. In the new variant of the disease (vCJD), large amounts of infectious proteins accumulate in the lymphatic tissue, including in the gastrointestinal tract. Therefore, vCJD endoscopic transmission is theoretically possible.

3) Kuru disease (laughing death) - until the middle of the twentieth century this killed women and children from the Fore tribe on the island of Papua New Guinea, who for ritual reasons were eating infectious fragments of relatives. People born after the ban on cannibalism (after 1959) no longer suffer from Kuru [7, 13, 14, 23, 25, 28, 29, 30].

\section{RISK STRATIFICATION}

A. Patient risk groups. People at risk of prion diseases can be divided into the following risk groups:

1) patients diagnosed with vCJD or suspected of vCJD disease (clinical symptoms);

2) patients diagnosed with CJD or suspected of having the possibility of CJD (clinical symptoms), people diagnosed with Sporadic Fatal Insomnia;

3) relatives of a patient with CJD (located in the second group at risk or deceased from CJD), unless the genetic form of the disease has been excluded;

4) recipients of human (non-recombinant) growth hormone, and patients who have had corneal transplantation or transplantation of a dura mater fragment;

5) patients with violent, unidentified central nervous system disease, of unknown origin, with dementia or without dementia and without a specific suspicion of CJD;

6) other people [31].

B. Risky treatments. Due to the recognized breakdown of the pathological prion protein in the patient's body, invasive procedures they have the following classification of high-risk operations.
I. Neurosurgical procedures involving the central nervous system (brain, spinal cord, optic nerve), dorsal root, trigeminal nerve, inner ear, pituitary gland or olfactory area nasal mucosa.

II. Ophthalmic surgery (involving the back of the eye, optic nerve) also a corneal transplant.

III. Other surgical interventions in contact with high-risk tissue (paranasal sinuses, maxillofacial organs, temporal lymph nodes, olfactory epithelium).

IV.A lumbar puncture for retrieval of cerebrospinal fluid samples (generally irrelevant, because single use equipment is commonly used).

V. In the case of vCJD - lymphatic system treatments, e.g. tonsillectomy, splenectomy, appendectomy, operation on the terminal ileum, lymphadenectomy, lymph node biopsy, bone marrow surgery (e.g. in orthopaedic or traumatic surgery).

Blood should be treated as a material of special danger only in the case of vCJD $[13,32]$.

Risk management. Before each invasive procedure, the patient should be examined for clinical or probable CJD symptoms (vCJD) to allow specific preventive measures to be taken. These measures are necessary if the infectious protein burden of the medical devices used exceeds the washing/ sanitizing efficiency of routine reprocessing procedures. This should be especially noted during high-risk procedures: neurosurgical and ophthalmic surgery, laryngology or oral surgery due to the distribution of the pathogens in the body [33].

The case is considered to be CJD if the patient exhibits symptoms of a neurologic multi-system disease that progresses rapidly. For example, the recent history of cortical dysfunction may be a reason for this assumption. Ophthalmic symptoms are the most common initial symptoms of CJD [33].

Risk management requires identification: (a) the endangered persons (risk groups of patients) and (b) high risk interventions (high risk operations).

The probability of infection caused by the use of a contaminated instrument depends not only on the residual contamination of the instrument, but also on the sensitivity of the operated tissue [31].

Danger from animal products. Meat meal and meat-bone meal produced, among others, from the bodies of sheep that died of scrapie, were used in cattle breeding in the first half of the 20th century in many countries. In the mid-1980s, hundreds of cases of BSE in cattle were found. Most cases were recorded in the United Kingdom, also in Portugal, Switzerland and Ireland. In Poland, only one case of detection of BSE was reported in 2002, in the area of Tarnów, Lubartów, Kluczbork and Zamość [22]. Sick cattle allow the transmission of the infectious agent to humans via the digestive tract $[13,34]$.

Danger from blood. The first victims of prions taken from asymptomatic blood donors may have been people with haemophilia, who were treated with donor plasma in Scotland or in England at the end of the 20th century [22].

Hospital infections. There are enormous problems related to the risk of transferring prions from patient to patient on 
the surface of instruments used in medical procedures. One way of proceeding involves quarantining the equipment used for surgery within the brain, tonsils or appendix, until the biopsy results of these organs are obtained, excluding, as far as possible, asymptomatic carriage of prions. Items of dental equipment, especially in contact with trigeminal nerve endings, as well as ophthalmic and other equipment, need special care [22].

Hygiene requirements for reprocessing thermolabile endoscopes. Sporadic Creutzfeldt-Jakob disease (CJD) occurs at a frequency of $1-2$ cases per million inhabitants annually. In individual cases, the transmission of CJD by contaminated medical devices has been reported. The pathogens show high tolerance to the usual procedures used in the reprocessing of medical devices [35, 36, 37].

The purpose of the procedures described below is to minimize the risk of transferring from patient to patient all forms of transmissible spongiform encephalopathies, through contaminated thermolabile endoscopes. The abnormal prion protein is thermally stable, extremely resistant to enzymatic activity, and after drying on a surface (including the inner surface of endoscopic channels) it is very difficult to remove or inactivate during a conventional decontamination process $[13,14,38]$.

Partially active procedures and chemicals in the elimination of prions on medical tools:

- $1 \mathrm{M} \mathrm{NaOH}$ solution, temperature $20^{\circ} \mathrm{C}$, minimum process time 1 hour $(\mathrm{pH}>10)$;

- 2.5-5\% $\mathrm{NaOCl}$ solution, temperature $20^{\circ} \mathrm{C}$, minimum process time 1 hour (at least 20,000 ppm active chlorine);

- steam sterilization (after appropriate preparation of instruments), temperature $134^{\circ} \mathrm{C}$, minimum time: 18 minutes; this process requires the installation of a special programme,

- 4M solution of guanidinium thiocyanate, temperature $20^{\circ} \mathrm{C}$, minimum process time: 2 x 30 minutes (total time: 60 minutes);

- gaseous hydrogen peroxide [13, 38-44].

Inactive procedures and chemical agents for prions: alcohols, aldehydes (including formaldehyde), ethylene oxide, iodine, dry heat, ionizing radiation, UV, acids [13, 38-44]. Contaminated materials should not be exposed to binding agents and should be kept moist during the period between use and disinfection by immersion in chemical disinfectants [38]. Preparing to reprocess thermolabile endoscopes after use, precautions should be taken, taking into account combinations of patient risk groups and highrisk treatments [31].

Procedures are divided into: (a) procedures in the case of recognizable (or suspected) risk - patients included in risk groups $1-5$, (b) procedures in the case of non-identifiable risk - patients classified as risk group 6 [31].

Procedure in the case of a recognizable risk (patients included in risk groups 1-5). Whenever possible and justified, disposable-use instruments for invasive surgery should be used in patients with definite, clinically probable cases of CJD (vCJD). After use, these tools should be incinerated. In the case of interventions in high-risk tissues, disposable-use instruments should be used, such as scalpels, biopsy needles, cannulas, medical equipment for subarachnoid anaesthesia and nerve conduction blocks, knives, lancets, thermolabile endotracheal tubes, bone drill bits and bone screws, that may be exposed to contact with the central nervous system or cerebrospinal fluid, implants $[29,31]$. If the use of disposable equipment is not possible, the treatment should be planned in advance, after careful consideration, to identify those medical devices that can be safely processed. Reprocessing of medical devices should consist of a combination of at least two processes suitable for inactivating prions (preferably one after the other) [31].

1. Pre-washing and washing. Drying of the tools and any activities that may cause coagulation of protein should be prevented. Pre-washing of medical devices should be performed immediately after use. Pre-washing is an important step in the regeneration of medical equipment, including flexible endoscopes. Improper cleaning or brushing of channels in the cleaning solution used for several endoscopes without replacement is a cross-contamination hazard for other medical devices. Immediately after completing the examination, without allowing drying, the external surface should be cleaned with disposable, moist compresses (wipes impregnated with alcoholic disinfectant must not be used, because this causes the fixation of impurities), all instrument channels must be thoroughly rinsed with water $[31,45]$. Only one endoscope should be placed in the bath/washbasin to prevent cross-contamination of the equipment. The endoscope should be completely disassembled so that all surfaces can be thoroughly cleaned. Demineralized or distilled water should be used throughout the decontamination process. Without allowing the device to dry, place the device in a disinfection bath/washbasin for pre-washing with a solution of a suitable and effective detergent, e.g. 4M guanidine thiocyanate. After complete immersion, each channel of the device should be thoroughly filled with the solution and rinsed with plenty of liquid. Each channel should be brushed repeatedly with a brush adapted to the diameter of the channel. The brushes should only be used to clean one endoscope. The equipment should be left in solution for 30 minutes at $20^{\circ} \mathrm{C}$. After the second washing and brushing of the channels, the equipment should be soaked in a $4 \mathrm{M}$ guanidine thiocyanate for the next 30 minutes to ensure a total process time of 60 minutes. After every cleaning of tools and thorough rinsing, the working solution must be changed. The solution of guanidinium thiocyanate should be thoroughly washed off the device after the recommended exposure time. Clean, fresh water must be used for each endoscope rinsing [7, 31, 43, 44, 46]. After rinsing, dry the channels and external surfaces with compressed air. This activity is very important, it removes water from the channels, allows the introduction of disinfectant and prevents its dilution, which is decisive for the effectiveness of its action. Do not dry thermally because can cause coagulation of the protein and thus its fixing $[31,46]$.

After use, the bath/washbasin must be thoroughly rinsed, mechanically cleaned, disinfected and dried. Chemical substances (e.g. alcohols, aldehydes, acids) or thermal processes used in the reprocessing of devices may negatively affect the counter-prion efficiency of the subsequent stages. Therefore, the pre-washing and washing process is of great importance [31]. Accurate manual detergent washing is the most important step in the endoscope reprocessing process, because any remaining contaminants can reduce the effectiveness of the subsequent stages of preparing 
the equipment for use. During manual washing, strict adherence to the parameters is important: contact time, temperature, detergent concentration, as recommended by the manufacturer, in order to ensure high process efficiency. It is impossible to effectively disinfect or sterilize equipment without its prior preparation [45-47].

2. Disinfection. Only clean (cleaned to the desired level) instruments are to be disinfected. Thermal/thermochemical processes may have a negative effect on the anti-prion efficiency of the process due to coagulation of proteins on insufficiently cleaned tools [31]. The neodisher SeptoClean tools preparation from Dr. Weigert $\mathrm{GmbH} \& \mathrm{Co}$ is used for the washing and disinfection of prions from endoscopic accessories. The product was tested for prionicidal activity according to the recommendation of the Robert Koch Institute. The test results confirmed the prionicidal effect of the preparation. Process parameters:

1) washing phase with anti-prion prophylaxis - $5 \mathrm{ml}$ of preparation $/ 1,000 \mathrm{ml}$ of working solution, temperature $55^{\circ} \mathrm{C}$, duration of action 10 minutes;

2) disinfection phase with prion decontamination - $10 \mathrm{ml}$ of preparation $/ 1,000 \mathrm{ml}$ of working solution, temperature $60^{\circ} \mathrm{C}$, duration of action 10 minutes.

These parameters guarantee a reduction of $>4 \log 10$ prion proteins [31]. During the process, it is important to adhere to the parameters determined during the tests. Particularly important parameters are: concentration of working solution, time of contact with chemicals, temperature during the process, concentration of hydrogen ions $-\mathrm{pH}$, lack of inhibiting materials, such as residual soiling, and confirmation that disinfection solutions are in contact with all parts of the endoscope $[45,46]$. Disposable items used for washing should be thrown away and incinerated, the disinfection bath must be thoroughly rinsed, mechanically cleaned, disinfected and dried after the process [31].

The technical and technological threats in manual decontamination are numerous and subject to human error. Therefore, it is preferable to carry out a machine washing and disinfection process which enables validation, registration and ongoing process control. After preliminary washing and rinsing in water, the instruments are mechanically cleaned and disinfected in a disinfecting washer. For this purpose, a programme without thermal drying is used. After completing the process, one empty washing cycle of the washer-disinfector should be performed [31, 46, 48].

3. Sterilisation. The thermostable elements of the endoscopic instrumentation and other accessories are subjected to a steam sterilization process at $134^{\circ} \mathrm{C}$, with a minimum process time of 18 minutes, provided that the pre-treatment (washing, disinfection) was carried out correctly. A special programme must be installed for this purpose [49]. Thermolabile endoscopes used in gastroenterology for all high-risk procedures performed in patients classified as risk groups 1 and 2 (patients diagnosed with CJD (vCJD) or suspected of $\mathrm{vCJD}$ disease) should be withdrawn from circulation after proper cleaning (described above). They should be considered potentially contaminated with invasive protein and stored, appropriately labelled, under strict supervision until diagnosis. Disposable items should be segregated and placed in a safe container for burning as waste. If the diagnosis has been confirmed or is still inconclusive, the equipment should be kept for re-use only with the same patient, after the washing and disinfection process, or sent for incineration $[31,50]$.

Procedure in the absence of identifiable risk (patients classified as risk group 6, and those suffering from dementia). 1) In the case of interventions in high-risk tissues, one-time use instruments should be used [29, 31]. 2) Reprocessing of standard medical devices should combine at least two procedures (ideally one after the other) that are at least partially suitable for disinfecting or inactivating prions. They include: a) pre-washing and washing, b) thermal/chemical-thermal disinfection, c) steam sterilization with proven effectiveness against prions; only thermostable elements can be subjected to this process $[42,49]$.

The technical and technological threats in manual decontamination are numerous and subject to human error. Therefore, it is preferable to run the washing and disinfection process using a machine which enables validation and ongoing process control [48].

Employee protection. When decontaminating endoscopic equipment, the principles of health and safety at work must be followed. In particular, the employee is obliged to use a waterproof apron, avoid skin contact with the working solution, protect the mouth and nose (and use gloves and safety glasses). When working with guanidinium thiocyanate solution, observe the following precautions: do not inhale or consume the solution, contact with it may cause skin, eye and respiratory irritation. Addition of acid to a solution of guanidine thiocyanate may cause the release of cyanides $[13,31,46,50]$.

Additional precautions. In an invasive medical procedure in the operating theatre for patients with prion pathogens, the spectrum for reprocessing medical devices should be critically analysed, in the first place the principle of minimizing contamination should be applied. The treatment should be planned at the end of the day. It should be performed in a room with a minimum number of medical personnel, with the minimum equipment, only with the equipment necessary for a given procedure, with the maximum use of disposable equipment. Supplementary equipment should be kept nearby (e.g. in the next room) [7]. After use, endoscopes should be transported to a processing room in closed containers [50].

Alternative procedures for the reprocessing of thermally unstable medical devices. The introduction of increasingly complex medical devices, made of different materials, for invasive medical operations requires the development of new reprocessing procedures. Sterilization procedures based on gaseous hydrogen peroxide can deactivate prions on the external and internal surfaces of medical devices which the sterilant reaches. The effectiveness of this method depends, inter alia, on the initial preparation of medical equipment, the type and nature of potentially contaminated surfaces and the concentration of $\mathrm{H}_{2} \mathrm{O}_{2}$ on the cleaned surfaces. It is believed that hydrogen peroxide gas is relatively stable, has a broad spectrum of activity, and is not harmful to the environment because it decomposes with the separation of water and oxygen $[43,51-53]$. 
Centralization of infrastructure and endoscopic equipment resources intended for patients included in risk groups $1-5$ is a solution that releases Health Care Facilities from responsibility for the quality of the reprocessing of this equipment for use $[13,31]$. One example is the University Medical Centre in Göttingen, Germany, which has endoscopes for hire. After use, the equipment is reprocessed according to the relevant guidelines or disposed of, if necessary. This solution is conducive to cost efficiency [31]. In Poland, there are currently no systemic solutions in this area.

\section{CONCLUSIONS}

1. Iatrogenic transmission of prions (equipment, therapy, medical treatments) is possible through: hormonal preparations, corneal and dural transplants, surgical instruments and medical equipment. The probability of prion infection through blood, sputum, saliva, nasal discharge, tears, urine or faeces, is considered to be very low $[29,49]$.

2. The reprocessing of medical devices used in a patient with suspicion or confirmed CJD (vCJD) disease should be performed using procedures and chemicals active against prions.

3. The performance of a procedure (especially invasive) in a patient with suspected or confirmed CJD (vCJD) disease must result in prophylactic measures: maximum use of disposable equipment, operating room equipped with only the necessary equipment, the use is recommended of a flexible endoscope intended only for this purpose in a region or country $[7,50]$.

4. Thermostable accessories should be sterilized in a moist heat at $134^{\circ} \mathrm{C}$, for 60 minutes (minimum time: 18 minutes), after proper preliminary stages of preparation [31, 50].

5. Proper handling (i.e. washing, reprocessing and storage) of flexible endoscopes and accessories is crucial to ensure the safety (i.e. preventing the transmission of iatrogenic infections via endoscopy) of all persons involved in the endoscopy, as well as in the procedures and maintenance of endoscopic devices [45-47].

6. The future of endoscopy will be shaped mainly based on the use of disposable - use endoscopic accessories. The project "Development of a disposable-use endoscopic tool" (DUET) can serve as an example of systemic solutions in this area. The EU-funded project was focused on the development of disposable endoscopes to reduce the risk of cross-infection and hospital-acquired infections. It demonstrated the possibility of constructing economically effective endoscopic equipment suitable for safe disposal after use, and in the future for recycling [54].

\section{REFERENCES}

1. Hwang S, Greenlee JJ, Vance NM, Nicholson EM. Source genotype influence on cross species transmission of transmissible spongiform encephalopathies evaluated by RT-QuIC. PLoS One. 2018; December 20. https://doi.org/10.1371/journal.pone.0209106

2. Hwang S, Nicholson EM. Thermodynamic characterization for the denatured state of bovine prion protein and the BSE Associated variant E211K. Prion. 2018; 12: 5-6, 301-309.

3. Igel-Egalon A, Bohl J, Moudjou M, Herzog L, Reine F, Rezaei H, et al. Heterogeneity and Architecture of Pathological Prion Protein Assemblies: Time to Revisit the Molecular Basis of the Prion Replication Process? Viruses 2019; 11(5), 429. https://doi.org/10.3390/v11050429
4. Urayama A, Concha-Marambio L, Khan U, Bravo-Alegria J, Kharat $\mathrm{V}$, Soto C. Prions efficiently cross the intestinal barrier after oral administration: Study of the bioavailability, and cellular and tissue distribution in vivo. Scientific Reports. 2016; 6:32338. https://doi. org/10.1038/srep/32338

5. Seed CR, Hewitt PE, Dodd RY, Houston F, Cervenakova L. CreutzfeldtJakob disease and blood transfusion safety. Vox Sang. 2018 Apr; 113(3): 220-231. https://doi.org/10.1111/vox./12631

6. Andréoletti O, Litaise C, Simmons H, Corbière F, Lugan S, Costes P, et al. Highly efficient prion transmission by blood transfusion. PLoS Pathog. 2012; 8:e1002782. [PubMed: 22737075].

7. Bonda DJ, Manjila S, Mehndiratta P, Khan F, Miller BR, Onwuzulike K, Puoti G, Cohen ML, Schonberger LB, Cali I. Human prion diseases: surgical lessons learned from iatrogenic prion transmission. Neurosurg Focus. 2016 Jul; 41(1): E10. https://doi.org/10.3171/2016.5.FOCUS/15126.

8. Hilton D. A. Pathogenesis and prevalence of variant Creutzfeldt- Jakob disease. J Pathol. 2006; 208: 134-141. https://doi.org/10.1002/path./1880

9. Ward HJ, Everington D, Croes EA, Alperovitch A, DelasnerieLaupretre N, Zerr I, et al. Sporadic Creutzfeldt-Jakob disease and surgery: a casecontrol study using community controls. Neurology. 2002; 59: 543-548.

10. Flechsig E, Hegyi I, Enari M, Schwarz P, Collinge J, Weissmann C. Transmission of scrapie by steel-surface-bound prions. Mol Med. 2001; 7: 679-684.

11. Taylor DM, Fraser H, McConnell I, Brown DA, Brown KL, Lamza KA, et al. Decontamination studies with the agents of bovine spongiform encephalopathy and scrapie. Arch Virol. 1994; 139: 313-326.

12. Head MW, Ironside JW. vCJD and the gut: implications for endoscopy. Gut. 2007 Jan; 56(1): 9-11. https//:doi.org/10.1136/gut./2006.101964

13. Axon AT, Beilenhoff U, Bramble MG, Ghosh S, Kruse A, McDonnell GE, et al. Guidelines Committee. European Society of Gastrointestinal Endoscopy (ESGE). Variant Creutzfeldt-Jakob disease (vCJD) and gastrointestinal endoscopy. Endoscopy. 2001; 33(12): 1070-80.

14. Kovaleva J, Peters FTM, van der Mei HC, Degenera JE. Transmission of Infection by Flexible Gastrointestinal Endoscopy and Bronchoscopy. Clin Microbiol Rev. 2013; 26 (2): 231-254.

15. Kazula A, Kazula E. Prion diseases - characteristics, diagnostics and therapy. Farm Pol. 2009; 65(8): 594-604.

16. Collinge J, Sidle KC, Meads J, Ironside J, Hill AF. Molecular analysis of prion strain variation and the aetiology of 'new variant' CJD.Molecular analysis of prion strain variation and the aetiology of 'new variant' CJD. Nature. 1996; 383(6602): 685-690.

17. Bruce ME, Will RG, Ironside JW, McConnell I, Drummond D, Suttie A et al. Transmissions to mice indicate that "new variant" CJD is caused by the BSE agent. Nature. 1997; 389(6650): 498-501.

18. Foliaki ST, Lewis V, Islam AMT, Ellett LJ, Senesi M, Finkelstein DI, et al. Early existence and biochemical evolution characterise acutely synaptotoxic PrP ${ }^{\mathrm{SC}}$. PLoS Pathogens. 2019; 15(4). https://doi.org/10.1371/ journal.ppat.1007712

19. Camp PJ, Damavandi PT, Pickersgill RW, Dove MT. Structure analysis of human Prion protein involved in Sporadic Fatal Insomnia. bioRxiv. 2018; 4. http://dx.doi.org/10.1101/314625doi

20. Prusiner SB. Prions. Proc Natl Acad Sci. USA. 1998; 95(23): $13363-$ 13383.

21. McDonnell G, Russell D. Antiseptics and disinfectants: activity, action, and resistance. Clin Microbiol Rev. 1999; 12(1): 147-179.

22. Hałat Z. Creutzfeldt-Jakob Disease (vCJD) in a capsule. Alergia. 2002; 4(15): 37-42.

23. Aguzzi A, Heppner FL. Pathogenesis of prion diseases: a progress report. Cell Death and Differentiation. 2000; 40(7): 889-902.

24. Nihat A, Mead S. Detection of Creutzfeldt-Jakob disease prions in skin: implications for healthcare. Genome Med. 2018; 10: 22. https:// doi.org/10.1186/s13073-018-0536-3

25. Glatzel M, Sigurdson CJ. Recent advances on the molecular pathogenesis of prion diseases. Brain Pathology. 2018; 29(2). https://doi.org/10.1111/ bpa.12693

26. Sigurdson CJ, Bartz JC, Glatzel M. Cellular and Molecular Mechanisms of Prion Disease. Annual Rev Pathol: Mechanisms Dis. 2019; 14: 497516. https://doi.org/10.1146/annurev-pathmechdis-012418-013109

27. Thapa S, Abdulrahman B, Abdelaziz DH, Lu L, Aissa MB, Schatzl HM. Overexpression of quality control proteins reduces prion conversion in prion-infected cells. J Biol Chem. 2018; 293(41): 16069-16082. https:// doi.org/10.1074/jbc.RA118.002754

28. Will RG, Ironside JW, Zeidler M, Cousens SN, Estibeiro K, Alperovitch A, et al. A new variant of Creutzfeldt-Jakob disease in the UK. Lancet. 1996; 347(9006): 921-925.

29. Bundesgesundheitsblatt-Gesundheitsforschung-Gesundheitsschutz. Variant of Creutzfeldt-Jakob Disease (vCJD). Epidemiology, Detection, 
Diag nostics and Prevention, with special emphasis on risk minimization of iatrogenic transmission by medical devices, in particular surgical instruments - Final Report of the vCJD Task Force on this topic. 2002; 45(4): 376-394.

30. Gielbert A, Thorne JK, Plater JM, Thorne L, Griffiths PC, Simmons $\mathrm{MM}$, et al. Molecular characterisation of atypical BSE prions by mass spectrometry and changes following transmission to sheep and transgenic mouse models. PLoS One. 2018; November 8. https://doi. org/10.1371/journal.pone.0206505

31. Recommendation of the Commission for Hospital Hygiene and Infection Prevention (KRINKO) at the Robert Koch Institute (RKI) and the Federal Institute for Drugs and Medical Devices (BfArM). Hygiene requirements for the reprocessing of medical devices. Bundesgesundheitsbl. 2012; 55: 1244-1310.

32. WHO. Guidelines on Tissue Infectivity Distribution in Transmissible Spongiform Encephalopathies. Geneva, Switzerland. 2006; 1-53.

33. Hamaguchi T, Noguchi-Shinohara M, Nakamura Y, Sato T, Kitamoto T, Mizusawa H, Yamada M. Ophthalmic surgery in prion diseases. Emerg Infect Dis. 2007; 13(1): 162-164.

34. Bons N, Mestre-Frances N, Belli P, Cathala F, Gajdusek D, Brown P. Natural and experimental oral infection of nonhuman primates by bovine spongiform encephalopathy agents. Proc Natl Acad Sci. USA. 1999; 96(7): 4046-4051.

35. Beekes M. The variant Creutzfeldt-Jakob Disease (vCJD) - Epidemiology and protective measures against human-to-human transmission. Bundesgesundheitsblatt Gesundheitsforschung Gesundheitsschutz. 2010; 53(6): 597-605.

36. Rutala WA, Weber DJ. Guideline for disinfection and sterilization of prion-contaminated medical instruments. Infect Control Hosp Epidemiol. 2010; 31(2): 107-117.

37. Simon D, Pauli G. Patient care and instrument sterilization in CJD patients and CJD suspected cases. Bundesgesundheitsblatt Gesundheitsforschung Gesundheitsschutz. 1998; 41(7): 279-285.

38. WHO. Geneva: World Health Organization; 1999. Infection Control Guidelines for Transmissible Spongiform Encephalopathies. http:// www.who.int/csr/resources/publications/bse/whocdscsraph2003. pdf?ua $=1$ (access: 2018.12.20)

39. Taylor DM. Inactivation of transmissible degenerative encephalopathy agents: A review. Vet J. 2000; 159(1): 10-17.

40. Qin K, O’Donnell M, Zhao R. Doppel: more rival than double to prion. Neuroscience. 2006; 141(1): 1-8.

41. Manuelidis L. Decontamination of Creutzfeldt-Jakob disease and other transmissible agents. J Neurovirol. 1997; 3(1): 62-65.
42. Bertram J, Mielke M, Beekes M, Lemmer K, Baier M, Pauli G. Inactivation and removal of prions in the preparation of medical devices - A contribution to the review and declaration of appropriate procedures. Bundesgesundheitsblatt Gesundheitsforschung Gesundheitsschutz. 2004; 47(1): 36-40.

43. Rutala WA, Weber DJ. Creutzfeldt-Jakob disease. Recommendations for disinfection and sterilization. Clin Infect Dis. 2001; 32(9): 1348-1356.

44. Beilenhoff U, Biering H, Blum R, Brljak J, Cimbro M, Dumonceau JM, et al. Reprocessing of flexible endoscopes and endoscopic accessories used in gastrointestinal endoscopy: Position Statement of the European Society of Gastrointestinal Endoscopy (ESGE) and European Society of Gastroenterology Nurses and Associates (ESGENA) - Update 2018. Endoscopy 2018; 50(12): 1205-1234.

45. SGNA (Society for Gastroenterology Nurses and Associates) Standards of Infection Prevention in Reprocessing Flexible Gastrointestinal Endoscopes. 2016.

46. Kovaleva J. Infectious complications in gastrointestinal endoscopy and their prevention. Best Pract Res Clin Gastroenterol. 2016; 30(5): 689-704.

47. Michel W, Frister H. Prophylaxis of vCJD transfer and machine methods of tool preparation. Aseptyka. 2002; 4(3): 17-18.

48. Pritzkow S, Wagenfuhr K, Daus ML, Boerner S, Lemmer K, Thomzig A, et al. Quantitative detection and biological propagation of scrapie seeding activity in vitro facilitate use of prions as model pathogens for disinfection. PLoS One. 2011; 6: e20384

49. Hookey L, Armstrong D, Enns R, Matlow A, Singh H, Love J. Summary of guidelines for infection prevention and control for flexible gastrointestinal endoscopy. Can J Gastroenterol. 2013; 27(6): 347-350.

50. Fichet G, Antloga K, Comoy E, Deslys JP, McDonnell G. Prion inactivation using a new gaseous hydrogen peroxide sterilisation process. J Hosp Infect. 2007; 67(3): 278-286.

51. Fichet G, Comoy E, Duval C, Antloga K, Dehen C, Charbonnier A, et al. Novel methods for disinfection of prion-contaminated medical devices. Lancet. 2004; 364(9433): 521-526.

52. Rogez-Kreuz C, Yousfi R, Soufflet C, Quadrio I, Yan ZX, Huyot V, et al. Inactivation of animal and human prions by hydrogen peroxide gas plasma sterilization. Infect Control Hosp Epidemiol. 2009; 30(8): 769-777.

53. Sivakumaran M. Transmission of BSE by blood transfusion. Lancet 2000; 356(9243): 1771-1772.

54. UE. Disposable endoscopes to reduce infection. 2008; Grant agreement ID:18294. https://cordis.europa.eu/result/rcn/87272_pl.html (access: 2019.02.26) 